\title{
Os mapas como "operadores espaciais" na construção da cidade de São Paulo do início do século XX
}

\author{
[ The maps as "spatial operators" in the construction of the \\ São Paulo city in the early twentieth century
}

\section{Eliane Kuvasney}

\begin{abstract}
RESUMO - Neste artigo busca-se compreender de que forma o ambiente de transformações do início do século XX influenciou e foi influenciado pela produção cartográfica, no caso específico dos mapas que estavam sendo produzidos representando a cidade de São Paulo e seu entorno. A hipótese deste trabalho é que a forma como a cartografia refletia as mudanças começou a participar da dinâmica da cidade e que os ingredientes dessa dinâmica (as ideias de crescimento e expansão, por exemplo) passaram a ser orientados pelos mapas, ou seja, os mapas tornaram-se "operadores espaciais". O objetivo principal da pesquisa é contribuir para o desenvolvimento de uma geo-história cartográfica na perspectiva de analisar os mapas como fatos/fenômenos sociais e assim refletir sobre a extensão e duração desses fenômenos na organização e funcionamento dos espaços das sociedades. PALAVRAS-CHAVE - Geo-história; cartografia; operadores espaciais;
\end{abstract}

São Paulo; século XX. • ABSTRACT - What is sought is how the early twentieth century transformations environment influenced and was influenced by cartographic production, in the case of maps that were being produced representing the city of São Paulo and its surroundings. The hypothesis is that the way the mapping reflected the changes began to take part in the city's dynamic and that the ingredients of this dynamic (the growth of ideas and expansion, for example) have to be guided by maps, thus turning maps into "spatial operators". The main objective of the research is to contribute to the development of a cartographic geohistory in the perspective of analyzing the maps as social facts/phenomena and thus reflect on the extent and duration of these phenomena on the organization and functioning of spaces of societies. $\cdot$ KEYWORDS - Geohistory; cartography; spatial operators; São Paulo; XXth century.

Recebido em II de abril de 2016 Aprovado em 6 de julho de 2016

KUVASNEY, Eliane. Os mapas como "operadores espaciais" na construção da cidade de São Paulo do início do século XX. Revista do Instituto de Estudos Brasileiros, Brasil, n. 64, p. I67-I82, ago. 2016.

DOI: http://dx.doi.org/Io.II6o6/issn.23I6-90IX.voi64pI67-I82

I Universidade de São Paulo (USP, São Paulo, SP, Brasil). 


\section{INTRODUÇão}

O espaço da metrópole paulistana hoje, observado a partir da cartografia, reforçada pela memória local e pela estrutura urbana herdada, nos apresenta poucos resquícios de seu passado colonial. Se associarmos a essa memória os dados demográficos, observaremos que a cidade, nos albores do século XX, começa a deixar para trás as marcas da vila colonial quase insignificante e sua condição primeva de "boca de sertão". A passagem do final do século XIX para o século $\mathrm{XX}$ traz consigo a cafeicultura, a expansão das ferrovias, levas de imigrantes, $\mathrm{o}$ começo da industrialização e os subúrbios, trazendo também uma forte tendência especulativa.

Era o início do século XX, numa São Paulo que crescia em termos populacionais (de 65.000 habitantes em I890 para 240.000 em I900, saltando para 580.000 em I920) e também na sua estrutura urbana. Na virada do século XIX para o século XX antigas chácaras ao redor do núcleo histórico da cidade estavam sendo loteadas, e as áreas urbana e suburbana se expandiam continuamente. Novos núcleos suburbanos surgiam. Ferrovias faziam a ligação do interior, onde se produzia o café, com o porto de Santos, por onde ele era exportado, e a bela e inglesa estação da Luz foi aberta aos passageiros em I90I. Além disso, com o dinheiro das exportações do café, São Paulo se firmava como o mais dinâmico centro comercial e financeiro da província. Como resultado, ainda no primeiro quartel do século $\mathrm{XX}$, estavam criadas as bases para o desenvolvimento industrial de São Paulo, com a transferência de capitais gerados na atividade agrária para as incipientes indústrias locais e, com elas, surgem os bairros industriais e operários.

Todas essas mudanças vêm acompanhadas também da modernização da infraestrutura urbana. Com a chegada da companhia Light, em I900, são instaladas linhas de bondes elétricos e os tramways, que ampliam os deslocamentos, aumentando a possibilidade de ampliação do tecido urbano. Observa-se também nesse período o surgimento de loteamentos populares localizados nos subúrbios, para dar vazão à demanda por moradia nessa cidade cuja população, em I930, alcança 900 mil habitantes. A canalização das águas do córrego Anhangabaú e 
depois a do rio Tamanduateí permitiram a urbanização da Várzea do Carmo². Alguns anos depois, as obras para retificação do Tietê foram iniciadas, com o mesmo objetivo. Dessa forma, essa cidade em transformação, que adentra o século $\mathrm{XX}$, configura-se como a gênese da metrópole paulistana. Nesse sentido, elencamos a cidade de São Paulo e seu entorno nos albores do século XX na perspectiva, "não de reconstituir todo o passado, mas revelar as condições e o momento onde se produziu a sua diferença. E procurar as razões da sua reprodução como espaço específico"3, o espaço de configuração da metrópole.

\section{OS “OPERADORES ESPACIAIS”. OS MAPAS COMO PROTAGONISTAS}

Parte-se do princípio de que qualquer objeto da sociedade possui uma dimensão espacial e que esta não se limita à sua localização. Todos englobam espaços de métricas, de escalas e de substâncias muito variadas4. Todos têm, portanto, sua espacialidade. Os operadores espaciais são, nesse sentido, "entidades que possuem uma capacidade a agir com "desempenho" no espaço geográfico das sociedades interessadas"s.

2 Várzea do Carmo era a denominação da atual região do Parque Dom Pedro, na área central da cidade de São Paulo, quando era frequentemente atingida pelas cheias do rio Tamanduateí. Após a canalização do rio, o topônimo caiu em desuso.

3 BRUNET, R. Mondes nouveaux. Tomo 1 da Géographie universelle. Paris: Belin/Reclus, 1990, p. 130.

4 Conforme LUSSAULT, Michel. L'homme spatial. La construction sociale de l'espace humain. Paris: Édition du Seuil, 2007, p. I47.

5 Ibidem, p. I9 


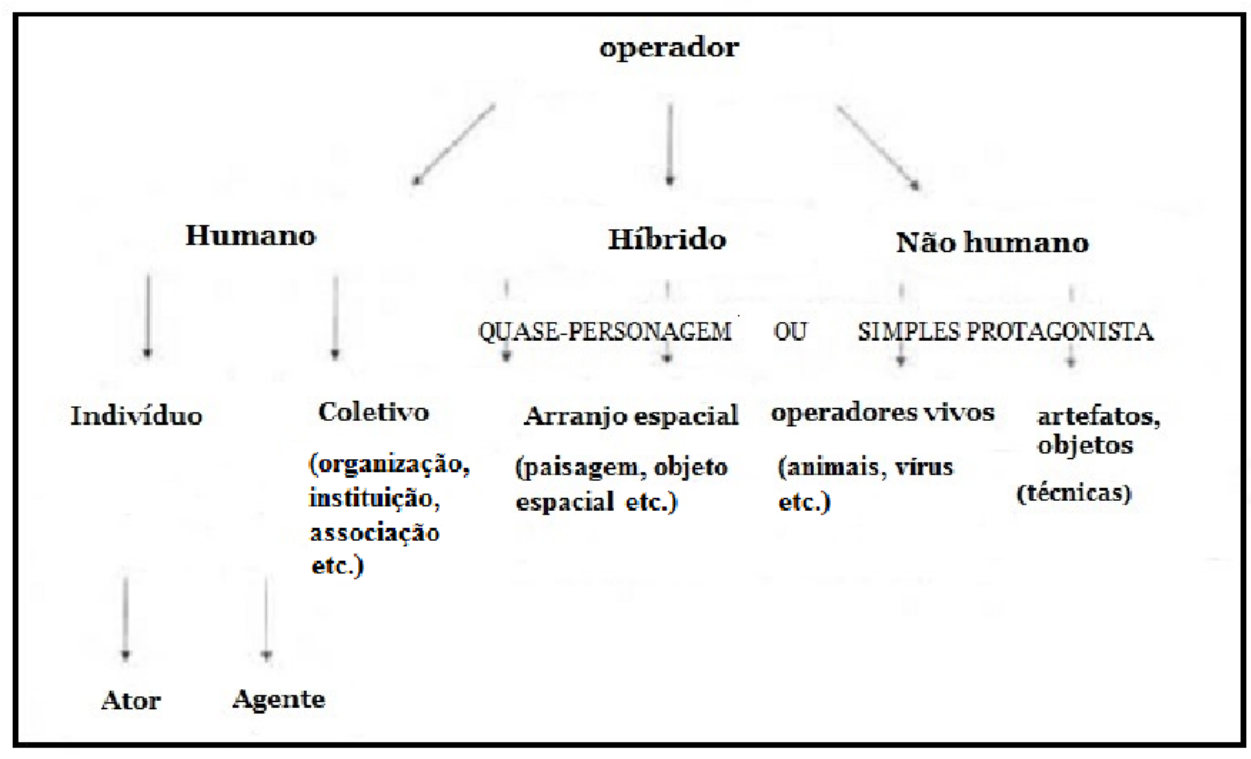

Figura I - Tipos de operadores espaciais. Fonte: LÉVY, Jacques e LUSSAULT, Michel. Logiques de l'espace, esprit des lieux. Paris: Belin, 2000 (Coleção Mappemonde). Adaptado de LUSSAULT, 2007, p. I49 (tradução nossa)

A figura 1 mostra os diferentes tipos de operadores humanos e não humanos. Michel Lussault lembra que os operadores não humanos são designados e construídos como tais pelos humanos. Estes definem sempre os limites que os separam do que lhes é externo, ao mesmo tempo que elaboram todos os métodos de apreensão - pelo homem - dos não humanos. Há, dessa forma, sempre uma parte de humanidade nos operadores não humanos. Estes, a partir das ações nas quais se inscrevem, são dotados por outros operadores - humanos e, portanto, dotados de competência enunciativa - de uma espécie de caráter e, quase personificados, tornam-se então "quase personagens" . Nessa investigação partimos da hipótese de que determinados mapas tornam-se operadores não humanos, mas - aparentemente - não seriam “quase personagens". Estes são aqueles que usam dos objetos para se exporem socialmente, ou seja, usam de um corpus iconográfico que os torna visíveis, daí a necessidade de distinguir os operadores não humanos simples (que operam, que o autor chama de "protagonistas") de operadores "quase-personagens", que ficam restritos ao estatuto de operadores humanos. Os mapas parecem encaixar-se na categoria de "simples protagonistas", em princípio, já que se trata de objetos materiais, artefatos. Caberá à pesquisa esclarecer até que ponto esses artefatos deixaram de ser simples protagonistas para - dotados de competência enunciativa que os hibridiza ("O mapa nos mostra", "o mapa nos informa”) - tornarem-se quase personagens.

6 Ibidem, p.I5I. 


\section{O protagonismo dos mapas em São Paulo}

Três plantas da cidade de São Paulo foram escolhidas para esta análise:

I) Planta geral da capital de São Paulo. Organisada sob a direcção do Dr. Gomes Cardim, intendente de obras, I897. Escala I:20.0007 (figura 4).

2) Planta geral da cidade de São Paulo. I905. Adoptada pela Prefeitura Municipal para uso de suas repartições. Levantada e organisada pelo Engenheiro Civil Alexandre Mariano Cococi e Luiz Fructuoso F. Costa, engenheiros da Commissão Geog. e Geologica. Escala: I:20.000 (figura 5).

3) Planta da cidade de São Paulo levantada pela Divisão Cadastral da $2^{\mathrm{a}}$ Secção da Directoria de Obras e Viação da Prefeitura Municipal - Edição provisória approvada pelo Acto n. 972, de 24 de agosto de I9I6. Escala I:20.0009 (figura 6).

As três têm em comum o fato de terem sido produzidas para o uso da Prefeitura de São Paulo, entre os anos I897 e I9I6, logo após a Proclamação da República, quando as Câmaras Municipais foram substituídas pelos Conselhos de Intendentes (não existindo a figura do prefeito até I9I4) e aqueles responsáveis pelos levantamentos e confecção das plantas da cidade estavam na Intendência do Serviço de Obras e Viação - até I9I4 - então nomeada Directoria de Obras e Viação, conforme vemos na planta de I9I6.

Por que essas três plantas? Além do fato de serem plantas organizadas pelo poder local, ao observarmos as plantas da cidade de São Paulo anteriores à de I897, como a planta organizada por Henry B. Joyner para a Cia. Cantareira e Esgotos, em I88I Io (figura 2), ou o Mappa da cidade de São Paulo e seus suburbios, organizado por Carlos Bresser, de $1847^{\text {II }}$ (figura 3) (ambos consistindo em plantas cadastrais), ou qualquer outro anterior a I897, vemos que a cidade é representada sempre em escalas que não ultrapassam I:Io.0oo e que essa se restringe ao núcleo central - o chamado

7 Planta Geral da Capital de São Paulo organisada sob a direcção do Dr. Gomes Cardin Intendente de obras. I897. Acervo Biblioteca Nacional. Disponível em: <http://objdigital.bn.br/objdigital2/acervo_digital/div_cartografia/ cart7I70I/cart7I70I.jpg $>$. Acesso em: Io maio 2016.

8 Planta geral da cidade de São Paulo I905 adoptada pela Prefeitura Municipal para uso de suas repartições. Levantada e organiszada pelo Engenheiro Civil Alexandre Mariano Cococi e Luiz Fructuoso F. Costa Engenheiros da Commissão Geo e Geologica. Acervo Biblioteca Nacional. Disponível em: <http://objdigital.bn.br/objdigital2/ acervo_digital/div_cartografia/cart523225/cart523225.jpg >. Acesso em: Io maio 2016.

9 Planta da Cidade de São Paulo levantada pela Divisão Cadastral da 2 a Secção da Directoria de Obras e Viação da Prefeitura Municipal - Edição Provisória approvada pelo Acto n. 972 de 24 de agosto de I9I6. Arquivo Público do Estado de São Paulo. Disponível em: 〈http://www.arquivoestado.sp.gov.br/site/acervo/repositorio_digital/ mapa_carto/BR_APESP_IGC_IGG_CAR_I_S_O2O2_OOI_OOI $>$. Acesso em: Io maio 2016.

Io Planta da cidade de São Paulo levantada pela Companhia Cantareira e Esgotos. Henry B. Joyner Engenheiro em Chefe. I88I. Arquivo Histórico de São Paulo. Disponível em: <http://www.arquiamigos.org.br/info/ info20/i-I88I.htm >. Acesso em: Io maio 2016.

II Mappa da cidade de São Paulo e seus suburbios. Feito por Ordem do Ex.mo Sr. Prez.te o Marechal de Campo Manoel da Fonseca Lima e Silva e pelo engenheiro civil C. A. Bresser. I847. Arquivo Histórico de São Paulo. Disponível em: 〈http://www.arquiamigos.org.br/info/info20/i-I847.htm〉. Acesso em: Io maio 2016. 
"triângulo" - e seu entorno imediato. É sabido que, em termos populacionais, a cidade passa de 30.000 habitantes na década de I870 para 65.000 em I890 e, desses, para 240.000 em I900, ou seja, nos últimos dez anos do século XIX, a população quase quadruplicou (e, num período de 30 anos, ela se multiplicou por oito), portanto, seria natural isso estar refletido nas plantas cadastrais da cidade. Mas as pesquisas nos levam a outras conclusões. Entre I905 e I9I6, apesar de observamos um crescimento no número de bairros na cidade, observamos também que ela se mantém adensada no seu núcleo central e entorno imediato, além da efetiva ocupação somente de bairros distantes desse núcleo, e que a área intermediária mantém uma baixíssima ocupação, apesar de as plantas nos mostrarem a cidade espraiando-se rapidamente.

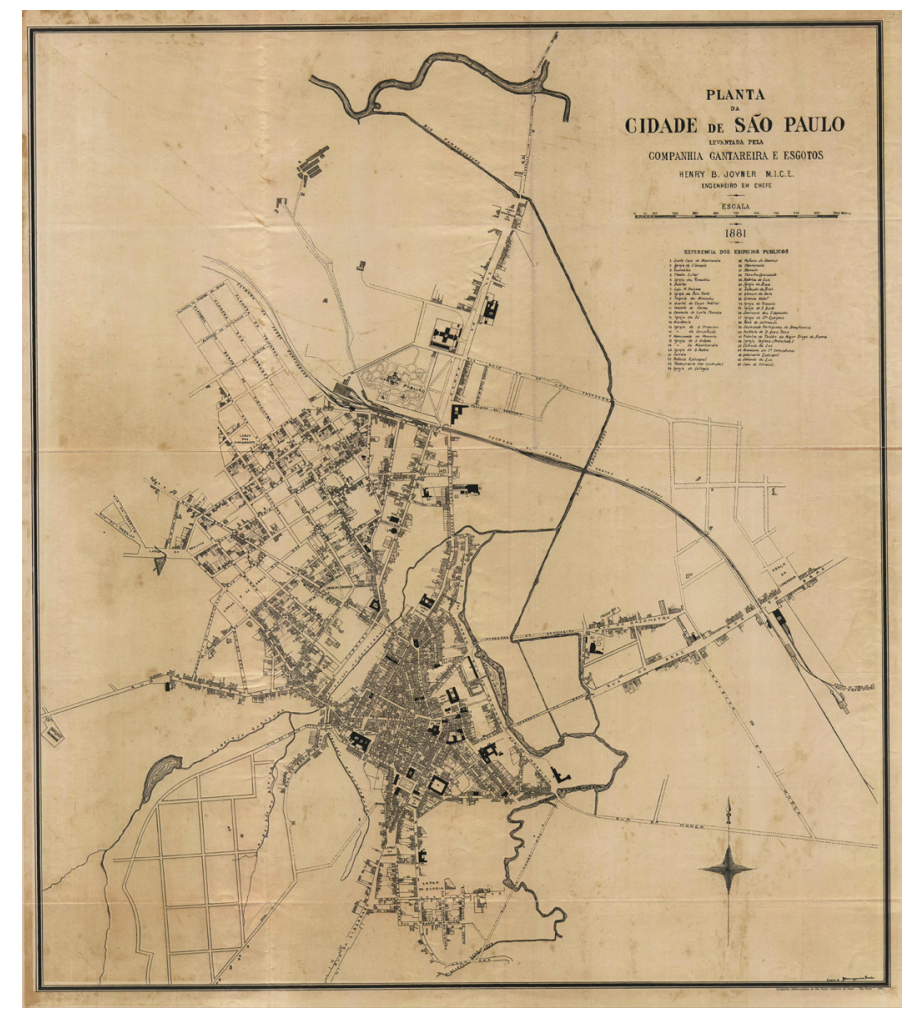

Figura 2 - Planta da cidade de São Paulo levantada pela Companhia Cantareira de Esgotos. Henry B. Joyner Engenheiro em Chefe. I88I. Escala I:Io.00o Fonte: Arquivo Histórico de São Paulo. Disponível em: 〈http://www.arquiamigos.org.br/info/infozo/i-I88I.htm〉 


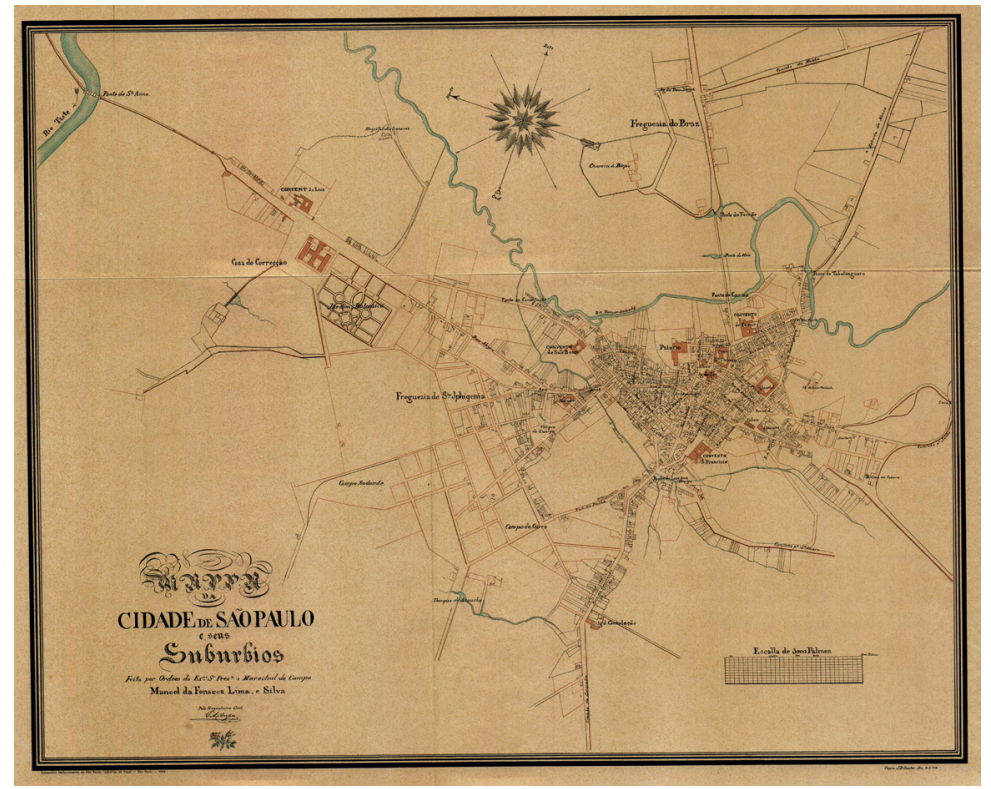

Figura 3-Mappa da cidade de São Paulo e seus suburbios. Feito por Ordem do Ex.mo Sr Prez.te o Marechal de Campo Manoel da Fonseca Lima, e Silva Pelo Engenheiro Civil C. A. Bresser. I847. Escala: I:I0.000. Fonte: Arquivo Histórico de São Paulo. Disponível em: 〈http://www.arquiamigos.org.br/info/info2o/i-I847.htm〉

Nesse sentido, mostraremos que as representações do espaço urbano a partir do final do século XIX operaram transformações no sentido de criar a ideia do espraiamento da cidade, que caracterizará a modalidade de crescimento - imposta - para a cidade ao longo do século XX.

A planta de I897 é uma novidade no que se refere à forma da cidade. Ao ser comparada, por exemplo, com a planta citada de I88I, chama a atenção, em primeiro lugar, pela ampliação da área do que seria propriamente a cidade, ou seja, observamos que a estrutura urbana representada mais que triplica em dezesseis anos. Em segundo lugar, pela mudança escalar: até então as plantas da cidade eram feitas em escalas até I:Io.ooo, o que significa que os núcleos além-Tamanduateí (leste do mapa) agora foram incorporados na representação da cidade e que esta também passa a incorporar trecho maior do rio Tietê, como feito nas plantas anteriores com o córrego Anhangabaú e também com o rio Tamanduateí, além de alguns núcleos além-Tietê. Vemos também assinalados os projetos de retificação dos rios Tamanduateí e Tietê, o que significa que a planta nos apresenta as intenções do poder público de ampliar o tecido urbano domando a natureza dos rios e das várzeas. 


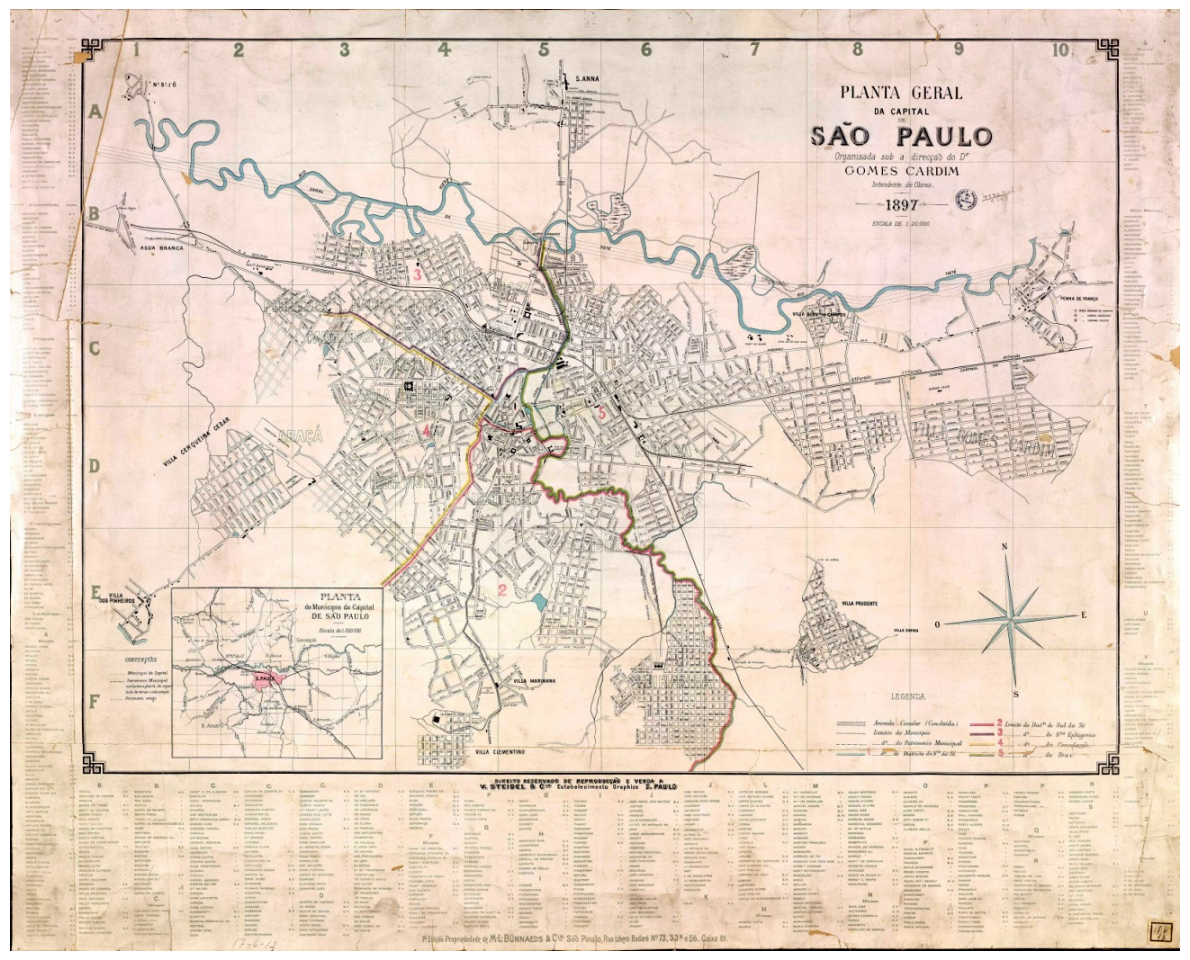

Figura 4- Planta geral da capital de São Paulo. Organisada sob a direcção do Dr. Gomes Cardim, intendente de obras, I897. Escala I:20.000. Fonte: Biblioteca Nacional. Disponível em: <http://objdigital.bn.br/objdigital2/acervo_digital/div_cartografia/cart7I70I/cart7I70I. jpg >

Lucia Noemia Simoni, após pesquisa em fontes documentais, afirma que o procedimento de elaboração dessa planta

[...]confere ao seu conteúdo um caráter antecipatório do que se pretendia realizar em terras dos arredores da cidade. Mas não se tratava de um projeto de cidade futura ou um plano, em sentido urbanístico [...]. Tratava-se sim de um mosaico de plantas de arruamentos particulares [em projeto, inexistentes] que preenchiam o lugar de uma racionalidade ansiada por parte da burocracia estadual e republicana ${ }^{\mathrm{I} 2}$.

Nesse sentido, Eudes Campos nos explica resumidamente a situação das terras do município, com o advento da República:

I2 SIMONI, Lucia N. A planta da cidade de São Paulo de I897: uma cartografia da cidade existente ou da cidade futura?. In: SIMPÓSIO LUSO-BRASILEIRO DE CARTOGRAFIA HISTÓRICA, 3. Ouro Preto, 2009. Anais.... Ouro Preto: UFMG, 2009, p.I5 (grifos meus). Disponível em: <https://www.ufmg.br/rededemuseus/crch/simoni_a-planta-da-cidade-de-sao-paulo-de-I897.pdf >. Acesso em: Io maio 2016. 
as Câmaras haviam sido suspensas e substituídas pelos Conselhos de Intendência Municipal e a Lei Estadual n. I6, de I3 de novembro de I89I, art.38, §I ${ }^{\circ}$, estabeleceu que, uma vez extinto o tradicional rossio (área que constituía o patrimônio municipal e dentro de cujos limites exerciam o seu poder as Câmaras Municipais), ficava criado em seu lugar nas povoações de mais de mil almas um círculo com seis quilômetros de raio. As terras devolutas contidas nesse círculo poderiam, em caso de necessidade, ser alienadas como forma de aumentar as rendas municipais. Fato que desencadeou um processo de natureza privatista que, no caso de São Paulo, se arrastava desde I852, quando a Câmara havia cogitado pela primeira vez pôr à venda os terrenos desocupados de seu patrimônio ${ }^{\mathrm{I3}}$.(

A planta em questão consiste em um conjunto de intenções - públicas e privadas - com relação ao futuro da cidade, que crescia vertiginosamente em termos populacionais, ao mesmo tempo que transformações sociais e econômicas ocorriam, como a abolição dos escravos, a proclamação da República, as levas de imigrantes, a cafeicultura... e uma elite cujas práticas permaneciam na lógica escravista e rentista de poder e de mando adquirida desde a colônia.

Interessante e esclarecedora é a pesquisa documental feita por José Inácio de Melo Souza no Arquivo Histórico de São Paulo - AHSP sobre esse período ${ }^{\text {I4 }}$. Esse pesquisador lembra que o crescimento vertiginoso da população da cidade pela via da migração interna e internacional gerou uma demanda gigantesca junto ao Serviço de Obras e Viação - SOV e, "para os engenheiros municipais, a falta de informações sobre a cidade era um dos entraves para a realização do trabalho de fiscalização" e que "a planta oficial da cidade era um dos instrumentos de trabalho do engenheiro". Porém, muitas permissões de construção em bairros afastados eram negadas pelos engenheiros do SOV, com a alegação de estarem em ruas "inexistentes" ou "sem nome”, apesar de sua existência na planta de I897. Tal situação de confronto entre os engenheiros do SOV e os proprietários e construtores ocorria em virtude dos muitos pedidos de legalização de construções em ruas que haviam sido abertas pelos próprios proprietários, sem a anuência da municipalidade - mas que constavam da planta de I897 - fato bastante comum desde a década de I850. Um caso relatado por ele merece destaque:

O prefeito tinha determinado que se recusasse alinhamento e aprovação de plantas para ruas que não fossem as oficiais. A reclamação de Heinsfurter [proprietário e construtor] se calçava no despacho favorável do prefeito, já que a avenida constava da planta oficial da cidade, contra o qual se insurgia Sá Rocha [o engenheiro responsável pelo parecer]. Para ele [o engenheiro], a planta oficial estava longe de ser um documento de licenciamento, mas, sim, de trabalho, "Tanto é assim que na relação oficial das ruas

I3 CAMPOS, Eudes. São Paulo antigo: plantas da cidade. Informativo Arquivo Histórico Municipal, 4 (20): set./out. 2008. <Disponível em: http://www.arquivohistorico.sp.gov.br>. Acesso em: Io maio 2016.

I4 SOUZA, José Inácio de Melo. José de Sá Rocha: engenheiro municipal - uma trajetória pessoal e a formação de um corpo técnico para gestão da cidade. Informativo do Arquivo Histórico de São Paulo, 9 (35): fev.20I4. <Disponível em: http://www.arquivohistorico.sp.gov.br >. Acesso em: Io maio 2016. 
da cidade, a qual me foi fornecida pela Prefeitura (e que aliás contém erros deploráveis principalmente em uma publicação oficial) se declara logo que: 'nem todas as ruas e suas denominações que figuram na planta foram aceitas pela Câmara ou Prefeitura”I5.

A planta de I897, tida como um mosaico de plantas e arruamentos particulares, como dito, não podia ser utilizada como planta oficial da cidade, mas a mesma assim foi confeccionada, o que sugere a anuência do intendente de Obras Municipais Pedro Augusto Gomes Cardim, experiente advogado e ex-procurador municipal. E foi esse o argumento utilizado no parecer do procurador do município, em favor do proprietário, naquela ocasião:

[...] "basta o fato dessa avenida e outras que formam a Vila Deodoro figurarem na planta da cidade levantada em I897 pelo Intendente de Obras [Gomes Cardim] para não se poder deixar de considerá-las como ruas oficiais” (grifo do documento). [...] Aos argumentos da Procuradoria em favor da legalização das ruas juntou-se outro, possivelmente da Secretaria Geral, afirmando a validade da planta de I897, já que, como era sabido, "grande parte" do antigo Arquivo da Intendência de Obras tinha desaparecido ${ }^{\mathrm{I}}$.

Melo Souza lembra ainda que esse parecer da procuradoria favorável ao proprietário "foi a primeira grande ‘anistia' para os moradores da cidade que tinham construído suas casas em ruas não legalizadas pela Câmara Municipal” e que isso voltaria a se repetir em I9I6 "quando Washington Luiz procedeu da mesma maneira, baseando-se na planta levantada pela $2^{a}$. Seção da DOV [então Directoria de Obras e Viação] naquele ano", tratando-se - em ambos os casos - de "reconhecimento da falência do controle urbano pela Câmara”.

Lucia Noemia Simoni, após esclarecer-nos o contexto em que a planta de I897 foi elaborada. conclui de forma semelhante sobre o poder público:

Nada de cartografias que trouxessem à luz as divisas entre as terras públicas e particulares, para que qualquer um pudesse se candidatar a elas e, sim, os apossamentos, as grilagens de terras, concessões havidas por requerimentos de sujeitos bem informados, que possivelmente não teriam sido mantidas caso tivesse existido um controle efetivo sobre o uso da terra ${ }^{17}$. 


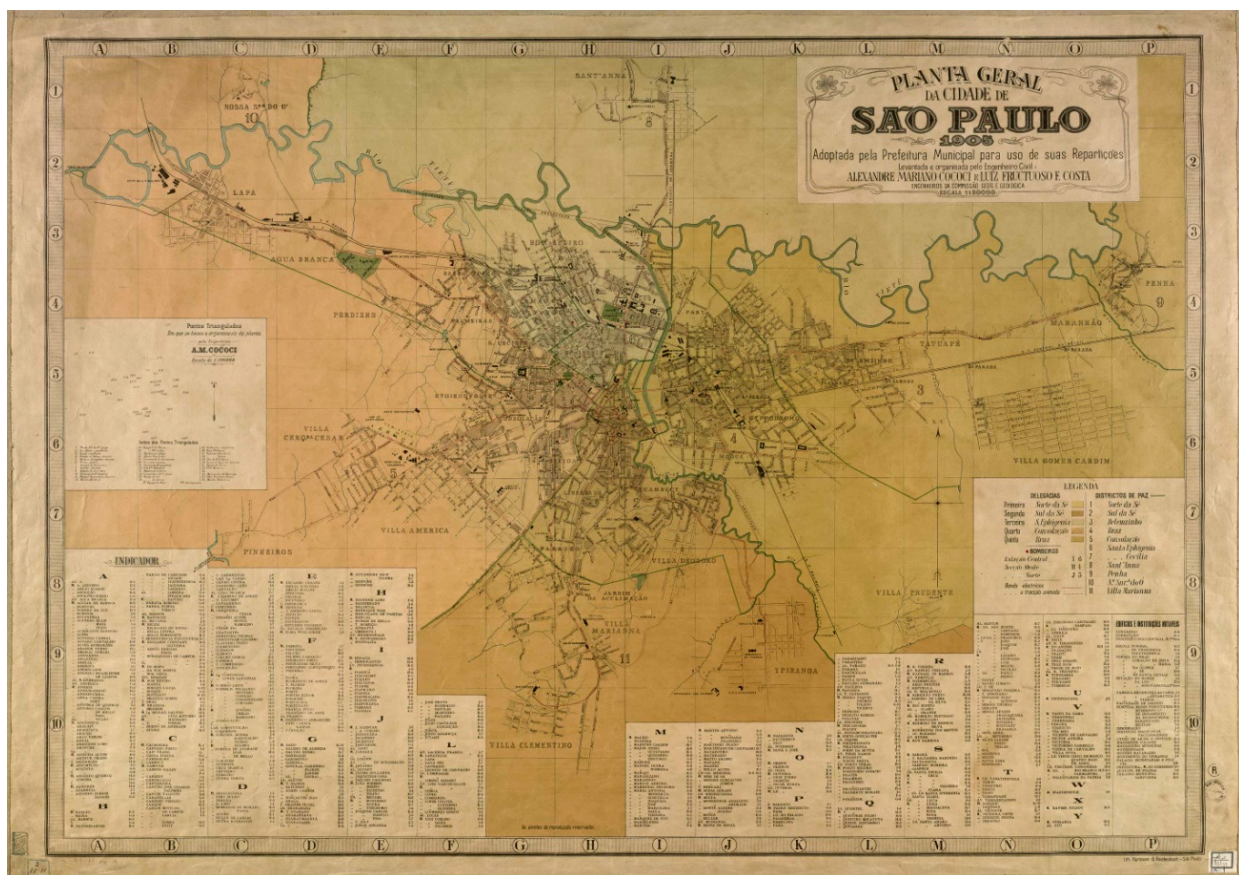

Figura 5-Planta geral da cidade de São Paulo. I905. Adoptada pela Prefeitura

Municipal para uso de suas repartições. Levantada e organisada pelo Engenheiro Civil Alexandre Mariano Cococi e Luiz Fructuoso F. Costa, engenheiros da Comissão Geog. e Geologica. Escala: I:20.00o. Fonte: Biblioteca Nacional. Disponível em:<http:// objdigital.bn.br/objdigital2/acervo_digital/div_cartografia/cart523225/cart523225.jpg>

Ao passarmos para as plantas de I905 e I9I6, vemos que permanece a escala adotada na planta de I897 e aparecem poucas alterações com relação aos loteamentos apresentados. As diferenças entre essas e a planta de I897 são, em geral, alterações no número de ruas ou na forma dos loteamentos - com predomínio das reduções no número de ruas, mostrando que os loteamentos arrolados em I897 estavam sendo paulatinamente implantados. Vejamos.

I - Alguns dos loteamentos arrolados na planta de I897 têm sua forma reduzida na planta de I905, como é o caso, no sul, do Ypiranga (reduzido a um quinto do número de ruas apresentado em I897), de Vila Prudente e do Cambucy (este último, também desmembrado em Cambucy e Vila Deodoro); na planta de I9I6, no entanto, o Ypiranga volta a apresentar o traçado de I897; um loteamento não nomeado, a leste, localizado entre a $3^{\mathrm{a}}$ e a $4^{\mathrm{a}}$ paradas da Central do Brasil, também tem sua forma reduzida nas plantas de I905 e I9I6, de mais de duas dezenas de ruas para seis; assim como o loteamento de Cerqueira César, a oeste, é reduzido à metade em I905, mas muda de traçado em I9I6, mais alongado no sentido NE/SO. Perdizes, a oeste, também tem seu traçado reduzido entre I897 e I905, mas também muda de traçado em I9I6, com outro formato, distinto do apresentado em I897.

2 - Observamos também o surgimento de alguns novos loteamentos nas plantas de I905 e I9I6, mas sempre em pontos periféricos da planta. Na extensão da estrada de 
ferro inglesa (Santos a Jundiaí), a noroeste, a Água Branca, apenas nomeada na planta de I897, é traçada em I905 e, em I9I6, é também incluído o parque de mesmo nome. Em ambas é representado também um novo núcleo, a Lapa, no limite noroeste da carta. A sudoeste, o traçado de Pinheiros permanece na planta de 1905 (também com redução de ruas), igualmente na planta de I9I6, e o núcleo do Butantã - o primeiro a transpor o rio Pinheiros - aparece somente em I9I6.

3 - Ainda no setor oeste, observamos que a Vila América só é nomeada na planta de I905, apesar de já estar parcialmente traçada em I897. Já na planta de I9I6 aparece toda a estrutura dos jardins Europa e América (garden city), porém sem ser nomeados. Também na planta de I9I6 o bairro da Mooca é ampliado na direção do Hipódromo. 4-Quanto às obras de retificação dos rios Tamanduateí e Tietê, os canais projetados se mantêm inalterados na planta de I905, o que indica a parte já construída de ambos. Na planta de I9I6 desaparece o canal projetado do Tietê e aparece o Tamanduateí retificado desde a foz, no rio Tietê, até o Ipiranga, juntamente com a nova avenida do Estado que o margeia.

5- Na planta de I9I6 estão demarcados os perímetros urbano e suburbano, além do perímetro central. Melo Souza lembra que

Somente durante o governo de Washington Luiz [I9I4-I9I9], foi que se estabeleceu um primeiro zoneamento da cidade, dividindo-a em urbana, suburbana e rural, com uma amplitude maior do que os perímetros anteriores, que não serviam para as edificações. Começando em Higienópolis, na rua Rio de Janeiro, seguia pela avenida Municipal (atual avenida Dr. Arnaldo), indo em linha reta pela alameda Santos, Domingos de Moraes, largo do Cambuci, rua da Mooca, Celso Garcia, Ponte Grande, avenida Tiradentes, estação da Barra Funda, largo dos Perdizes, Conselheiro Brotero até o fecho na Rio de Janeiro (bairros que antes estavam de fora como Vila Mariana, Barra Funda e Cambuci passavam à zona urbana). O subúrbio compreendia a Penha, Vila Gomes Cardim, Voluntários da Pátria, Carandiru, Água Branca, rua Guaicurus, Cerqueira César, Matadouro, Vergueiro, Ipiranga, fechando a zona pelo ribeirão Tatuapé. A zona rural cobria os limites do perímetro suburbano até as divisas do município ${ }^{\mathrm{I8}}$.

6 - A novidade nessas duas plantas é que os lotes efetivamente ocupados ("com construções”, como aparece na legenda da planta de I9I6) estão assinalados por áreas sombreadas, o que não existe na carta de I897, impossibilitando comparações em relação à efetiva ocupação naquele ano (o que reforça o fato de tratar-se de mosaico de plantas). Ali, o traçado dos loteamentos só nos mostra a expressão da vontade dos poderes público e privado com relação à morfologia urbana, não nos mostra sua efetivação através das construções (como nas plantas de I905 e I9I6) ou de seu uso (como na planta da Comissão Geográfica e Geológica de I9I4, não incluída nesta série), o que daria seu sentido de ocupação e, portanto, de espaço urbano e suburbano.

I8 SOUZA, José Inácio de Melo, op. cit. 


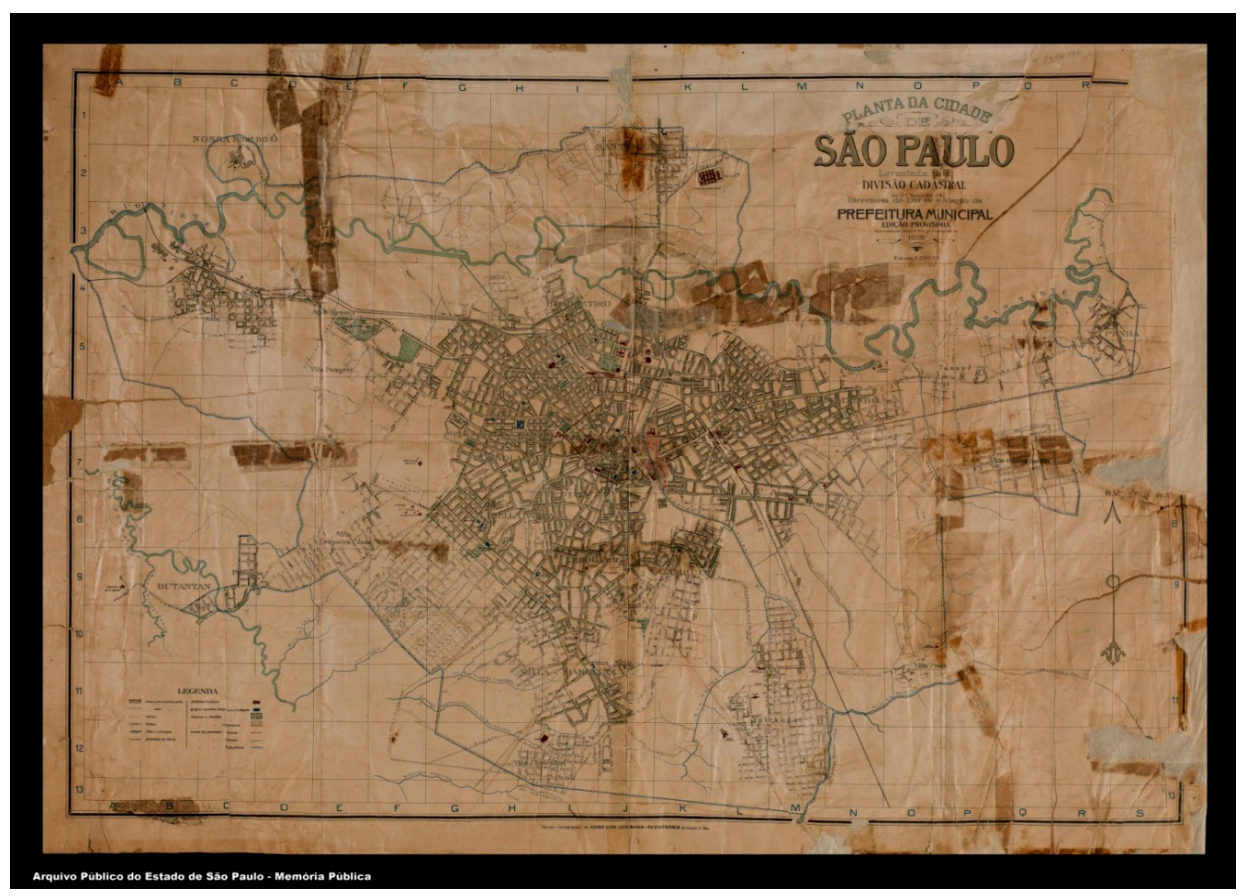

Figura 6 - Planta da cidade de São Paulo. Levantada pela Divisão Cadastral da 2 a Secção da Directoria de Obras e Viação da Prefeitura Municipal - Edição Provisória approvada pelo Acto n. 972, de 24 de agosto de I9I6. Escala I:20.000. Fonte: Arquivo Público do Estado de São Paulo. Disponível em:〈http://www.arquivoestado.sp.gov.br/site/acervo/ repositorio_digital/mapa_carto/BR_APESP_IGC_IGG_CAR_I_S_0202_00I_00I>

A observação dessa área sombreada, a partir da planta de I9I6, indica que ela está quase totalmente envolvida pelo perímetro urbano estabelecido pelo Acto $972^{\text {I9 }}$ que dá origem à planta, excedendo esses limites em poucos pontos em toda a carta. Ao compararmos essa área com aquela da planta de I905, elas são perturbadoramente semelhantes, mantendo a mancha pouco alterada nesses dez anos. Existem ampliações ao norte, entre Pari e Bom Retiro, e a oeste, entre Perdizes e Higienópolis. No perímetro suburbano destacam-se os loteamentos periféricos somente. Aqueles intermediários, entre a mancha propriamente dita e a periferia da carta e da cidade de I9I6, apresentam percentual muito baixo de construções. Essa situação é semelhante nas duas plantas.

O que é efetivamente ocupado no subúrbio em I9I6? A oeste, Lapa, Perdizes, parte de Pinheiros e Freguesia do Ó, além de parte das ruas Guaycurus, Cardoso de Almeida, Rebouças e Teodoro Sampaio (artérias de ligação com a zona urbana); a leste, a Penha

I9 Acto 972 de 24 de agosto de I9I6 "Considera publicas, para todos os efeitos municipaes, todas as ruas, avenidas e praças, com os respectivos nomes, constantes da 'Planta da Cidade de S. Paulo', levantada pela Directoria de Obras e Viação". Disponível em: <http://www.dicionarioderuas.prefeitura.sp.gov.br/PaginasPublicas/SeculoXX. aspx $>$. Acesso em: Io maio 2016. 
e a sua ligação com a zona urbana, a avenida Celso Garcia; ao norte, além-Tietê, a rua Voluntários da Pátria, o acesso a Santana e, no sul, a avenida Domingos de Moraes, Ipiranga e Vila Prudente também apresentam algumas construções esparsas.

Toda a área suburbana entre o perímetro urbano e os bairros periféricos, nos extremos do perímetro suburbano - e que envolve grandes loteamentos já presentes na planta de I897 ou incorporados na de I9I6 - apresenta pouca ou nenhuma edificação em I9I6. No entanto, estamos vendo a forma da cidade de São Paulo, com seu espraiamento sendo "naturalmente" construído nessas imagens.

A planta de I897, em especial, apresenta-se como um operador espacial. Michel Lussault afirma que o operador "pode ser dotado, por ele mesmo ou pelos outros, de uma essência, ou seja, de um discurso de ficção que substancializa e naturaliza competências pragmáticas adquiridas no fogo da ação"º . Ao observar a forma e as condições sob as quais essa planta foi feita, sabemos que se trata de um discurso de ficção ou, como afirmado por Simoni, de um "conjunto de intenções" ${ }^{2 I}$ daqueles que econômica e politicamente controlavam as terras do município - e que dotaram a planta desse discurso que naturalizou a imagem da cidade espalhada. As demais plantas apenas mantiveram o discurso, o que o reforçou substancialmente e o manteve como prática até os dias atuais.

Neste ponto da pesquisa destacamos que operadores humanos dotaram a planta de um discurso que naturalizou a imagem da cidade espalhada. Aqui, faz-se necessário retomar a questão inicial: até que ponto os mapas deixaram de ser simples protagonistas para - dotados de competência enunciativa que os hibridiza tornarem-se "quase-personagens"? Nesse sentido, e para reafirmar a ideia de que os mesmos podem ser vistos dessa forma, cabe aqui a ideia de "coprodução" de Kitchin, Dodge e Perkins, que - baseados na teoria do ator-rede ${ }^{22}$, de Latour - afirmam:

Mapas não têm significado ou ação por conta própria; eles são parte do conjunto de pessoas, processos discursivos e coisas materiais. Eles estão inseridos em uma rede de atores e de práticas, em vez de existirem, a priori, como objetos de conhecimento não ideológicos. A teoria do ator-rede, então, busca fornecer uma mais ampla e mais rica compreensão da criação de mapas por meio de atores-rede específicos (por exemplo, agência de mapeamento nacional) e o uso de mapas como operadores dentro de vários atores-redes [...] por considerar as diversas práticas cotidianas, as interações e a circulação de ideias e de poder entre diversos atores (pessoas, textos, objetos, dinheiro) $)^{23}$.

\footnotetext{
20 LUSSAULT, Michel, op. cit. p.150.

2 I SIMONI, Lucia N., op. cit.

22 LATOUR, B. Reagregando o social. Uma introdução à teoria do ator-rede. Tradução Gilson César Cardoso de Sousa. Salvador: EDUFBA; Bauru: Edusc, 2012.

23 KITCHIN, R.; PERKINS, C.; DODGE, M. Thinking about maps. In: __ (Eds.) Rethinking maps. Routledge, 2009. p. 16 (tradução nossa).
} 
Nesse sentido, os mapas são coparticipantes de redes de operadores, que envolvem - no caso da planta de I897 - a Intendência de Obras, a Câmara, os loteadores e os proprietários, além - é claro - da própria planta, que materializa as ações dos demais agentes e promove a naturalização da cidade espalhada.

\section{Conclusão}

Buscou-se, com este texto, iniciar uma discussão sobre o uso dos mapas como operadores espaciais, como agentes na construção da metrópole que temos hoje: uma cidade espalhada, adensada em seu centro e nas suas bordas. Uma cidade que desde o início dessa construção foi desigual. O que seria a marca da modernidade nesse processo? Trata-se da modernidade subjacente na cidade que crescia nas suas bordas, que ultrapassava os rios, que os transformava em canais, a cidade da belle époque, das garden cities, dos bonds eléctricos, da ferrovia, das indústrias. Todos eles presentes na cidade que crescia nas quatro direções cardeais e todos eles presentes no discurso da naturalização dessa forma da cidade através dos mapas.

Por se tratar de pesquisa em andamento, nesse primeiro momento analisamos as três plantas produzidas pelo e para o poder local. A continuidade desse trabalho implica analisar outras plantas produzidas no período de forma que aprofunde a compreensão da ação dos operadores nesse processo de coprodução da cidade, buscando sempre, como dito, entender essa cidade em transformação que adentra ao século XX, buscando "revelar as condições e o momento em que se produziu a sua diferença. E procurar as razões da sua reprodução como espaço específico"²4.

\section{SOBRE A AUTORA}

ELIANE KUVASNEY doutoranda no Programa de Pós-graduação em Geografia Humana (PPGH) do Departamento de Geografia da Faculdade de Filosofia, Letras e Ciências Humanas da Universidade de São Paulo. Bolsista CNPq. Programa USP/Cofecub, parceria entre a Universidade de São Paulo e o Comité Français d'Evaluation de la Coopération Universitaire avec le Brésil.

Email: ekuvas@gamail.com

24 BRUNET, R., op. cit., p.I3o. 


\section{REFERÊNCIAS BIBLIOGRÁFICAS}

BRUNET, R. Mondes nouveaux. Tomo I da Géographie Universelle. Paris: Belin/Reclus, I990.

CAMPOS, Eudes. São Paulo antigo: plantas da cidade. Informativo Arquivo Histórico Municipal, 4 (20): set./ out.2008. Disponível em: 〈http://www.arquivohistorico.sp.gov.br >. Acesso em: Io maio 2016.

KITCHIN, R.; PERKINS, C.; DODGE, M. Thinking about maps. In: (Ed.) Rethinking maps. Routledge, 2009.

LATOUR, B. Reagregando o social. Uma introdução à teoria do ator-rede. Salvador: EDUFBA; Bauru: Edusc, $20 I 2$.

LÉVY, Jacques; LUSSAULT, Michel. Logiques de l'espace, esprit des lieux. Paris: Belin, 2000. (Coleção Mappemonde).

LUSSAULT, Michel. L'homme spatial. La construction sociale de l'espace humain. Paris: Édition du Seuil, 2007.

SIMONI, Lucia N. A planta da cidade de São Paulo de I897: uma cartografia da cidade existente ou da cidade futura?. In: SIMPÓSIO LUSO-BRASILEIRO DE CARTOGRAFIA HISTÓRICA, 3. Ouro Preto, 2009. Anais... Ouro Preto: UFMG, 2009. Disponível em: <https:/www.ufmg.br/rededemuseus/crch/ simoni_a-planta-da-cidade-de-sao-paulo-de-I897.pdf >. Acesso em: тo maio 2016

SOUZA, José Inácio de Melo. José de Sá Rocha: engenheiro municipal - uma trajetória pessoal e a formação de um corpo técnico para gestão da cidade. Informativo do Arquivo Histórico de São Paulo, 9 (35): fev.20I4. Disponível em: http://www.arquivohistorico.sp.gov.br. Acesso em: Io maio 2016. 